\title{
HEALTH LITERACY IN KIDNEY DISEASE: ASSOCIATIONS WITH QUALITY OF LIFE AND ADHERENCE
}

\author{
Une Elisabeth Stømer $\mathbb{1}^{1,2}$, Astrid Klopstad Wahl ${ }^{3}$, Lasse Gunnar Gøransson ${ }^{2,4}$, Kristin Hjorthaug Urstad (i) ${ }^{1}$ \\ ${ }^{1}$ Faculty of Health Science, University of Stavanger, Stavanger, Norway \\ ${ }^{2}$ Department of Nephrology, Stavanger University Hospital, Stavanger, Norway \\ ${ }^{3}$ Faculty of Medicine, University of Oslo, Oslo, Norway \\ ${ }^{4}$ Department of Clinical Medicine, Faculty of Medicine, University of Bergen, Bergen, Norway
}

Elisabeth Stømer U., Klopstad Wahl A., Gunnar Gøransson L. and Hjorthaug Urstad K. (2020). Health literacy in kidney disease: associations with quality of life and adherence. Journal of Renal Care 46(2), 85-94.

\section{S U M M A R Y}

Background: Health literacy (HL) is a multidimensional concept with significance for self-management and health outcomes in patients with chronic kidney disease (CKD); however, research with a multidimensional perspective on $\mathrm{HL}$ is scarce.

Objectives: This study aimed to explore the relationship between multidimensional $\mathrm{HL}$, quality of life (QoL) and adherence to long-term therapy in CKD patients.

Design: A descriptive single-centre cross-sectional study.

Participants: Patients with CKD in stages 3-5 were recruited from the nephrology unit in a Norwegian hospital.

Measurements: The Health Literacy Questionnaire (HLQ) was used to assess HL, QoL was measured by the Short Form-12 (SF-12) and a Visual Analogue Scale (VAS-QoL). Adherence to long-term therapy was measured by the Medical Adherence Rating Scale 5 (MARS-5), participants' prescription withdrawals from pharmacies, and a VAS (VAS-adherence). Hierarchical cluster analysis was performed to group patients with similar HLQ scores, and multiple linear regression analysis was performed to identify the $\mathrm{HL}$ dimensions that were associated with QoL and adherence to long-term therapy.

Results: A total of 187 patients were included, 65\% were male, and the mean (SD) age was 67 (13) years. The high-level HL group $(\mathrm{N}=52)$ had significantly better QoL than patients in the mid-level $(\mathrm{N}=106)$ and low-level $(\mathrm{N}=27) \mathrm{HL}$ groups. The HL dimensions "actively managing health," "actively engage with healthcare providers," "ability to find good health information" and "ability to understand health information" were predictive of QoL and adherence to long-term therapy. Conclusion: $\mathrm{HL}$ seems to be important for both QoL and adherence to long-term therapy.

KEY WORDS Adherence to long-term therapy $\bullet$ Chronic kidney disease $\bullet$ Health literacy $\bullet$ Patient-reported outcome measures $\bullet$ Quality of life

\section{B IO D ATA}

Une Elisabeth Stømer is a PhD candidate at the Faculty of Health Sciences at the University of Stavanger, Norway. She is an intensive care nurse (ICN) with a master's degree in Health Sciences (MHS). Her working experience is from the intensive care unit (ICU) and the Dialysis Unit in the Department of Nephrology at Stavanger University Hospital in Norway. Her focus is currently on Health literacy in chronic kidney disease.

\section{CORRESPONDENCE}

Une Elisabeth Stømer, Faculty of Health Science,

University of Stavanger, Stavanger, Norway

Email: une.stomer@uis.no

This is an open access article under the terms of the Creative Commons Attribution-NonCommercial License, which permits use, distribution and reproduction in any medium, provided the original work is properly cited and is not used for commercial purposes. 


\section{INTRODUCTION}

Chronic kidney disease (CKD) is globally recognised as a major public health problem, and the disease affects $>10 \%$ of the Norwegian population (Hallan et al. 2006; Eckardt et al. 2013; Bruck et al. 2016). Patients living with CKD at all stages report lower quality of life (QoL) compared with the general population (Perlman et al. 2005; Osthus et al. 2010; Fructuoso et al. 2011; Pagels et al. 2012; Nabolsi et al. 2015).

It is recommended that patients with CKD lead a healthy lifestyle involving physical activity and avoid smoking (K/DOQI 2002). They often have a high pill burden (Bailie et al. 2005; Chiu et al. 2009; Levey et al. 2009; Whaley-Connell et al. 2011; Levey \& Coresh 2012; Tangkiatkumjai et al. 2017), and patients with advanced CKD must adhere to fluid and diet restrictions as well as renal replacement therapy to optimise their health (Levey et al. 2009). It is well-known that adherence to these health recommendations can be challenging (Chiu et al. 2009; Muntner et al. 2010; Clark et al. 2014).

In general, the World Health Organisation (WHO) reports that adherence to long-term therapy in patients with chronic illnesses averages $50 \%$ in developed countries and that the consequences of non-adherence are poor health outcomes and increased health care costs (WHO 2003). For CKD patients, in particular, adherence to long-term therapy is crucial to avoid unnecessary progression and life-threatening complications of the disease (Levey et al. 2009; Levey \& Coresh 2012). According to the conceptual model for $\mathrm{HL}$ described by Sorensen et al. (2012) high or adequate $\mathrm{HL}$ is a prerequisite for desirable health outcomes such as good QoL and sound health behaviour. Hence, knowledge about associations between $\mathrm{HL}$ and QoL and adherence to long-term therapy is valuable.

\section{LITERATURE REVIEW}

A concept of growing interest for health outcomes and selfmanagement in patients with chronic diseases is health literacy (HL) (WHO 2013; Mackey et al. 2016; Taylor et al. 2017; van der Heide et al. 2018). HL is defined as a multidimensional concept, encompassing the cognitive and social skills that determine the motivation and ability to gain access to, understand and use information in ways that promote and maintain good health (WHO 1998). Earlier research utilising multidimensional assessment tools for $\mathrm{HL}$ showed that CKD patients have $\mathrm{HL}$ deficits in domains relating to attending to one's health needs and understanding health information (Lambert et al. 2015). Recent research also shows associations between demographic and clinical variables such as sex, level of education, number of medications and depressive symptoms, and $\mathrm{HL}$ (Stømer et al. 2019). Further, low HL in CKD patients is associated with undesirable health behaviour, increased hospitalisation and mortality rates as well as impaired QoL (Grubbs et al. 2009; Cavanaugh et al. 2010; Magacho et al. 2011; Fraser et al. 2013; Green et al. 2013; Ricardo et al. 2014; Devraj et al. 2015; Kazley et al. 2015; Lambert et al. 2015; Demian et al. 2016; Dodson et al. 2016; Taylor et al. 2016). However, the majority of these studies rely on $\mathrm{HL}$ assessed with tools that solely measure health-related reading and numeracy skills. In recent years, the concept of $\mathrm{HL}$ has evolved from being about individual reading and numeracy skills to a broader concept including social, critical and interactive dimensions such as support from family and friends, cooperation with healthcare providers and critical thinking (Sørensen et al. 2012; Batterham et al. 2017; van der Heide et al. 2018). Consequently, new knowledge is needed about the associations between this broader definition of $\mathrm{HL}$ and outcomes such as QoL and adherence to long-term therapy both in general and in CKD patients in particular.

Hence, this study aimed to compare QoL and adherence to longterm therapy in patients with CKD with different levels of $\mathrm{HL}$. It will also aim to identify the specific $\mathrm{HL}$ dimensions associated with QoL and adherence to long-term therapy in patients with CKD.

\section{MATERIALS AND METHODS STUDY DESIGN AND PARTICIPANTS}

The current study was a single-centred descriptive crosssectional study. The study sample is previously described (Stømer et al. 2019), but in short, patients with CKD stages 3-5 were recruited from the outpatient clinic and the haemodialysis unit at the Nephrology Department. Two hundred and fortynine patients met the inclusion criteria and were asked to participate. One hundred and eighty-seven patients approved (response rate 78\%). Patients with noncutaneous cancer, unstable cardiovascular disease, a significant vascular incident (myocardial infarction, transient ischaemic attack or cerebral vascular accident) or major surgery within the last three months, were not included because we wanted to avoid patients in acute medical crisis. An acute medical crisis is likely to be overwhelming and decisive for the results of HLQ, QoL and adherence, and would probably not reflect the situation of living with CKD. The study was approved by the Data Protection Officer at the hospital, ID number 2017/1. 


\section{MEASUREMENTS}

We used patient-reported outcome measures (PROMs) to assess $\mathrm{HL}, \mathrm{QoL}$ and adherence to long-term therapy, including both medical adherence and adherence to lifestyle recommendations. Clinical data (renal function, comorbidities) and information about the collection of prescribed medications were retrieved from the medical records.

We assessed $\mathrm{HL}$ with the $\mathrm{HL}$ Questionnaire (HLQ), which is a multidimensional tool containing 44 items across nine independent scales that provides information about different dimensions of $\mathrm{HL}$. The HLQ scales are described in Table S2 (Osborne et al. 2013). The HLQ is divided into two parts. In the first part (HLQ scales 1-5), the respondents have four options to indicate how strongly they disagree or agree with a set of statements (strongly disagree, disagree, agree and strongly agree), with a possible range of scores from 1 to 4 . In the second part (HLQ scales 6-9), the respondents have five options to indicate how difficult or easy different $\mathrm{HL}$ tasks are (cannot do, usually difficult, sometimes difficult, usually easy and always easy), with a possible range of scores from 1 to 5 . The HLQ has no total summative score and no cut-off for inadequate $\mathrm{HL}$, however, higher scores indicate better $\mathrm{HL}$ (Osborne et al. 2013).

QoL was assessed with the Short Form-12 (SF-12) and a Visual Analogue Scale (VAS-QoL). The SF-12 is a non-disease-specific questionnaire containing 12 items resulting in two-component scores, the physical component score (PCS-12) and the mental component score (MCS-12). The SF-12 is derived from and comparable to the full SF-36 questionnaire, which is validated for CKD (Ware \& Sherbourne 1992; Ware et al. 1996, 1998; Osthus et al. 2012). To evaluate the patients' global QoL during the preceding four weeks, a VAS was used (VAS-QoL) (de Boer et al. 2004). The patients were asked to mark a point on the line that represented their general QoL, where the left vertical anchoring line represented "the worst imaginable QoL" and the right "the best imaginable QoL". The distance from the left anchoring line to the marked point was measured in $\mathrm{mm}$, and a higher number indicated better QoL, with a possible range of scores from 0 to 100. A single-item VAS has been validated for assessing general QoL in medical settings (de Boer et al. 2004).

Adherence to long-term therapy was measured by assessing medical adherence and adherence to lifestyle recommendations. Medical adherence was assessed by the Medical
Adherence Rating Scale 5 (MARS-5) and by registering the prescription collection from the pharmacy. The MARS-5 is a non-disease-specific questionnaire containing five items concerning general statements of medication-taking habits. The MARS-5 has been used across different chronic conditions, including asthma, diabetes, hypertension and mental illness. The total score ranges from 5 to 25 , where 25 is the best possible score and indicates perfect medical adherence (Jonsdottir et al. 2009; Sjolander et al. 2013). Adherence to medical treatment was also assessed by checking the participants' collection of medical prescriptions. Prescribed medications are obtained from the pharmacy for a maximum of three months of usage. If the prescribed medications were not collected for the previous three months, we defined the patient as nonadherent to medical treatment.

Adherence to lifestyle recommendations from healthcare providers was assessed using a VAS (VAS-adherence). The left anchoring line read "never follow lifestyle recommendations from healthcare providers," and the right anchoring line read "always follow lifestyle recommendations from healthcare providers," with a possible range of scores from 0 to 100 . There was no cut-off score for non-adherence, but a higher number indicated better adherence. A single-item VAS is validated for self-assessing medical adherence (Kalichman et al. 2009), we used it to assess adherence to lifestyle recommendations.

Beck Depression Inventory SF (BDI-SF) was used to assess depressive symptoms (Furlanetto et al. 2005). The BDI-SF has been used to assess depressive symptoms in CKD patients across different stages of the disease (Andrade et al. 2010). The questionnaire contains 13 items concerning guilt, pessimism, suicidal thoughts and other depressive symptoms. The maximum possible score is 39 and indicates severe depression. We used BDI-SF as a continuous variable to correct for depressive symptoms in the regression models.

Renal function was assessed using the CKD-EPI creatinine equation as the estimated glomerular filtration rate (eGFR) (Levey et al. 2009). The patients were thereafter classified into different CKD stages (K/DOQI 2002). Renal function, renal diagnosis, time with known CKD, comorbidities as expressed by the Davies comorbidity index $(\mathrm{DCl})$, and the number of prescribed medications were extracted from the patients' medical records. 


\section{STATISTICAL ANALYSIS}

IBM SPSS Statistics for Windows, Version 25.0. (IBM Corp., Armonk, NY) was used for the statistical analysis. Categorical data are presented as frequencies and percentages, and continuous data are presented as the means and standard deviations (SD) if normally distributed or as the medians and ranges if non-normally distributed. We performed Ward's hierarchical cluster analysis to identify patients with similar HLQ profiles. Ward's minimum variance method was run with standardised z-scores (number of SD from the mean) on each HLQ scale (Ward 1963). The number of clusters chosen was based on the minimum accepted number of cases in the smallest group. Kruskal-Wallis was used to compare QoL (PCS-12, MSC-12 and VAS-QoL) and adherence to long-term therapy scores (MARS5, VAS-adherence) among the different clusters, and between patients with different stages of CKD. Mann-Whitney was used as post hoc tests to identify where the differences were located. We used a $\chi^{2}$ test to compare the withdrawal of medical prescriptions from the pharmacy between the different clusters. Multiple linear regression analysis was performed in the whole group of patients to identify associations between QoL
(PCS-12, MCS-12 and VAS-QoL) and adherence to long-term therapy (VAS-adherence and MARS-5) as dependent variables and the nine HLQ scales as independent variables. Independent variables were included in the model if univariate analysis resulted in a $p<0.2$ and was excluded from the model in a manual backward manner if $p>0.05$. $p \leq 0.05$ were considered as statistically significant (Altman 2018). The dependent variables (PCS-12, MCS-12, VAS-QoL, MARS-5 and VAS-adherence) were used as continuous variables in the analysis. All regression models were corrected for age, sex, level of education and depressive symptoms (BDI-SF scores).

\section{RESULTS}

A total number of 187 patients were included in the study, 80 patients with CKD stage 3, 81 with CKD stages 4-5 not on haemodialysis and 26 haemodialysis patients. The mean age was 67 years (SD, 13), and 65\% were male. Forty percent of the participants had higher education, and the mean (SD) number of prescribed medications was 7.5 (3.7). Patient characteristics are previously described (Stømer et al. 2019) and are presented in Table 1.

\begin{tabular}{|c|c|c|c|c|}
\hline & $\begin{array}{l}\text { Total group } \\
(\text { no }=187)\end{array}$ & $\begin{array}{l}\text { Low-level } \\
(\text { no }=27)\end{array}$ & $\begin{array}{l}\text { Mid-level } \\
(\text { no = 106) }\end{array}$ & $\begin{array}{c}\text { High-level } \\
(\text { no }=52)\end{array}$ \\
\hline Age in years, mean $\pm S D$ & $67 \pm 13$ & $69 \pm 11$ & $67 \pm 13$ & $66 \pm 13$ \\
\hline Male sex, no (\%) & $122(65)$ & $11(40)$ & $73(70)$ & $37(71)$ \\
\hline \multicolumn{5}{|l|}{ Education level, no (\%): } \\
\hline Low $=\leq$ higher secondary school & $113(60)$ & $22(81)$ & $62(59)$ & $28(53)$ \\
\hline High $=>$ higher secondary school & $73(40)$ & $5(19)$ & $43(41)$ & $24(46)$ \\
\hline \multicolumn{5}{|l|}{ Household income in NOK, no (\%): } \\
\hline Low $=\leq 300,000$ & $37(20)$ & $9(33)$ & $21(20)$ & $7(13)$ \\
\hline Average $=>300,000$ & $147(80)$ & $18(67)$ & $83(80)$ & $44(85)$ \\
\hline Living alone, no (\%) & $49(26)$ & $11(40)$ & $28(27)$ & $9(13)$ \\
\hline \multicolumn{5}{|l|}{ DCl score, no (\%): } \\
\hline 0 & $66(35)$ & $8(30)$ & $34(32)$ & $24(46)$ \\
\hline 1 & $88(47)$ & $13(48)$ & $50(47)$ & $25(48)$ \\
\hline 2 & $33(18)$ & $6(22)$ & $22(21)$ & $3(6)$ \\
\hline \multicolumn{5}{|l|}{ Stage of CKD, no (\%): } \\
\hline 3 & $80(43)$ & $10(13)$ & $48(60)$ & $22(28)$ \\
\hline 4 and 5 , not on dialysis & $81(43)$ & $11(14)$ & $44(54)$ & $24(30)$ \\
\hline Haemodialysis patients, & $26(14)$ & $6(23)$ & $14(54)$ & $6(23)$ \\
\hline BDI-SF, median (range) & $2(0-29)$ & $3(0-29)$ & $2(0-25)$ & $0(0-19)$ \\
\hline Medications, mean (SD) & $7.5 \pm 3.7$ & $9.1 \pm 3.2$ & $7.7 \pm 3.8$ & $6.1 \pm 3.2$ \\
\hline \multicolumn{5}{|l|}{ Renal diagnosis, no (\%): } \\
\hline Hypertensive nephropathy & $62(33)$ & $7(26)$ & $31(29)$ & $22(42)$ \\
\hline Glomerulonephritis & $40(22)$ & $6(22)$ & $22(21)$ & $12(23)$ \\
\hline Diabetic nephropathy & $23(12)$ & $5(19)$ & $14(13)$ & $4(7)$ \\
\hline Other & $62(33)$ & $9(33)$ & $39(37)$ & $14(38)$ \\
\hline Time with CKD in months, median (range) & $46(1-515)$ & $81(1-270)$ & $41(1-516)$ & $50(2-278)$ \\
\hline
\end{tabular}

Table 1: Patient characteristics of the overall sample and patients with different levels of health literacy.

BDI-SF: Beck Depression Inventory Short Form; CKD: chronic kidney disease; DCl: Davies Comorbidity Index (DCl: 0 means no comorbid condition; DCl: 1 means 1-2 comorbid conditions and DCl: 2 means $\geq 3$ comorbid conditions); NOK: Norwegian kroner. 


\begin{tabular}{|c|c|c|c|c|}
\hline & $\begin{array}{l}\text { Low-level HL } \\
\qquad N=27\end{array}$ & $\begin{array}{l}\text { Mid-level HL } \\
\mathrm{N}=106\end{array}$ & $\begin{array}{l}\text { High-level HL } \\
\qquad \mathrm{N}=52\end{array}$ & P-values \\
\hline PCS-12 & & & & Low vs. high $=0.002$ \\
\hline Median (range) & $33.5(16.3-55.3)$ & $34.5(13.2-60.0)$ & $42.9(18.7-59.9)$ & $\begin{array}{l}\text { Low vs. mid }=0.524 \\
\text { Mid vs. high }<0.001\end{array}$ \\
\hline MCS-12 & & & & Low vs. high $=0.003$ \\
\hline Median (range) & $46.7(15.4-60.7)$ & $49.5(23.8-66.1)$ & $57.1(27.4-65.0)$ & $\begin{array}{l}\text { Low vs. mid }=0.012 \\
\text { Mid vs. high }=0.520\end{array}$ \\
\hline VAS-QoL & & & & Low vs. high $=0.001$ \\
\hline Median (range) & $50(10-100)$ & $68(9-100)$ & $82(19-100)$ & $\begin{array}{l}\text { Low vs. } \text { mid }=0.044 \\
\text { Mid vs. high }=0.002\end{array}$ \\
\hline \multicolumn{5}{|l|}{ MARS-5 } \\
\hline Median (range) & $24(14-25)$ & $24(13-25)$ & $24(18-25)$ & 0.852 \\
\hline VAS-adherence & & & & Low vs. high $=0.300$ \\
\hline Median (range) & $90(36-100)$ & $85(20-100)$ & $92(48-100)$ & $\begin{array}{l}\text { Low vs. mid }=0.393 \\
\text { Mid vs. high }=0.012\end{array}$ \\
\hline \multicolumn{5}{|c|}{$\begin{array}{l}\text { Table 2: Nonparametric tests to compare the quality of life and adherence to long-term therapy scores in patients with different levels of } \\
\text { health literacy. }\end{array}$} \\
\hline \multicolumn{5}{|c|}{$\begin{array}{l}\text { HL: health literacy; MARS-5: Medical Adherence Rating Scale 5; MCS-12: mental component score; Nonparametric tests: Kruskal-Wallis to find } \\
\text { differences between three different groups and Mann-Whitney as post hoc tests to identify where the differences are located. PCS-12: physical } \\
\text { component score; QoL: quality of life; VAS-adherence: Visual Analogue Scale for adherence to lifestyle recommendations; VAS-QoL: Visual } \\
\text { Analogue Scale for Quality of Life. }\end{array}$} \\
\hline
\end{tabular}

\section{QOL AND ADHERENCE IN PATIENTS WITH DIFFERENT HL LEVELS}

By using Wards' hierarchical cluster analysis, the patients were divided into three different groups with similar HLQ profiles. In our sample, the different groups were characterised by all-over low, medium and high levels of HL (Ward 1963). Twenty-seven patients (14\%) were in the low-level group, 52 (28\%) were in the high-level group and 106 (57\%) were in the mid-level group (Table 1) (Stømer et al. 2019).

Significantly better QoL, as assessed by the SF-12 (PCS-12, MCS-12) and VAS-QoL, was found in the high-level group compared with the low-level group (Table 2). The mid-level group had significantly higher MCS-12 and VAS-QoL scores than the low-level group and significantly lower MCS-12 and VAS-QoL scores than the high-level group. The PCS-12 scores were not significantly higher in the midlevel group compared with the low-level group of patients.

The VAS-adherence scores were significantly higher in the highlevel group compared with the mid-level group, while the score in the low-level group was not significantly different from those in the two other groups. The MARS-5 scores did not differ among the groups with different levels of HL (Table 2).

One hundred and forty-four (77\%) of the included patients gave consent for the researchers to access the E-prescription module in their medical record to evaluate the collection of prescribed medication from the pharmacy. Medical adherence, as evaluated by the collection of prescribed medication, was $50 \%$ in the lowlevel HL group (10/20), 60\% in the mid-level group (49/82) and $69 \%$ in the high-level group (29/42). However, the collection of prescribed medication was not significantly different among the groups.

The PCS-12 scores were significantly higher in patients with CKD stage 3 versus patients with CKD stage 4 and 5 not on dialysis $(p<0.001)$ and patients on haemodialysis $(p<0.001)$. VAS-QoL was significantly lower in haemodialysis patients versus patients with CKD stage $3(p=0.01)$. There were no differences between patients with different stages of CKD in MARS-5 or VAS-adherence scores (additional table).

\section{QOL AND ADHERENCE ASSOCIATED WITH DIFFERENT HL DIMENSIONS}

The HLQ scale number 9, "ability to understand health information well enough to know what to do," was positively associated with the PCS-12 and VAS-QoL, indicating that a greater ability to understand health information was associated with better physical and global QoL. HLQ scale number 3, "actively managing health" and scale number 6, "ability to actively engage with healthcare providers" were positively associated with the VAS-adherence, indicating that being active in managing their health and having the ability to engage with healthcare providers were associated with higher adherence to 


\begin{tabular}{|c|c|c|c|c|c|c|c|c|c|}
\hline \multirow[b]{3}{*}{ HLQ scales } & \multicolumn{3}{|c|}{ PCS-12 } & \multicolumn{3}{|c|}{ MCS-12 } & \multicolumn{3}{|c|}{ VAS-QoL } \\
\hline & Uni & MA & MaB & Uni & MA & MaB & Uni & MA & MaB \\
\hline & p & p & p (beta) & $\mathbf{p}$ & p & p (beta) & $\mathbf{p}$ & $\mathbf{p}$ & p (beta) \\
\hline Healthcare provider support & 0.370 & 0.210 & & 0.463 & 0.687 & & 0.045 & 0.815 & \\
\hline Have sufficient information & 0.025 & 0.570 & & 0.060 & 0.685 & & 0.024 & 0.661 & \\
\hline Actively managing health & 0.043 & 0.027 & & 0.317 & 0.677 & & 0.600 & 0.734 & \\
\hline Social support & 0.412 & 0.686 & & 0.119 & 0.352 & & 0.010 & 0.044 & \\
\hline Critical appraisal & 0.436 & 0.202 & & 0.120 & 0.810 & & 0.104 & 0.901 & \\
\hline Actively engaged & 0.010 & 0.970 & & 0.007 & 0.972 & & 0.003 & 0.939 & \\
\hline Navigating the healthcare system & 0.001 & 0.491 & & 0.001 & 0.661 & & 0.001 & 0.964 & \\
\hline Find good health information & 0.002 & 0.150 & & 0.001 & 0.134 & & 0.003 & 0.130 & \\
\hline Understand health information & 0.000 & 0.007 & $<0.001(4.733)$ & 0.001 & 0.688 & & 0.000 & 0.002 & $<0.001(9.238)$ \\
\hline Adjusted $\mathrm{R}^{2}$ & & & 0.221 & & & & & & 0.278 \\
\hline
\end{tabular}

Table 3a: Multiple linear regression analysis to identify associations between quality of life (SF-12 and VAS-QoL) and Health Literacy Questionnaire scales.

beta: unstandardised coefficient; MA: multiple regression analysis with all independent variables, MaB: multiple regression analysis after including independent variables if univariate analysis $p<0.2$ and stepwise backward elimination if $p>0.05$; MCS-12: mental component score-12; PCS-12: physical component score-12; VAS-QoL: Visual Analogue Scale-quality of life, Uni: univariate regression analysis,

lifestyle recommendations. The HLQ scale number 8, "ability to find good health information," was negatively associated with VAS-adherence, indicating that the ability to find health information was associated with lower adherence to lifestyle recommendations from healthcare providers. The MARS- 5 was not associated with any of the HLQ scales (Tables $3 a$ and $3 b$ ).

\section{DISCUSSION}

Our study shows that CKD patients with high overall levels of $\mathrm{HL}$ have better QoL and are more adherent to lifestyle recommendations than patients with lower HL. Understanding health information seems to be important for patients' QoL, whereas the ability to engage with healthcare providers as well as actively managing health appears to play a role in terms of adherence.
Our findings are consistent with those of an Australian study, including 100 haemodialysis patients, in which both physical and mental aspects of QoL were better in patients with high overall $\mathrm{HL}$ than in patients with low overall $\mathrm{HL}$ (Dodson et al. 2016). The association between the ability to understand health information and better QoL might be explained by patients' improved knowledge of how to minimise the risk of CKD progression, for example, understanding how to keep blood pressure well-regulated and how to manage diabetes mellitus (Roy et al. 2013; Chang et al. 2015). Our findings, as well as earlier research, show that lower renal function is associated with worse QoL (Fructuoso et al. 2011; Pagels et al. 2012). Furthermore, challenges in understanding health information may cause stress and anxiety, which may also affect QoL. A

\begin{tabular}{|c|c|c|c|c|c|c|}
\hline \multirow[b]{3}{*}{ HLQ scales } & \multicolumn{3}{|c|}{ MARS-5 } & \multicolumn{3}{|c|}{ VAS-adherence } \\
\hline & Uni & MA & MaB & Uni & MA & MaB \\
\hline & p & p & p (beta) & $\mathbf{p}$ & p & p (beta) \\
\hline Healthcare provider support & 0.303 & 0.726 & & 0.003 & 0.423 & \\
\hline Have sufficient information & 0.179 & 0.167 & & 0.001 & 0.349 & \\
\hline Actively managing health & 0.389 & 0.740 & & 0.000 & 0.000 & $<0.001(11.198)$ \\
\hline Social support & 0.634 & 0.941 & & 0.001 & 0.343 & \\
\hline Critical appraisal & 0.508 & 0.309 & & 0.296 & 0.132 & \\
\hline Actively engaged & 0.719 & 0.237 & & 0.026 & 0.053 & $0.016(5.357)$ \\
\hline Navigating the healthcare system & 0.254 & 0.161 & & 0.564 & 0.086 & \\
\hline Find good health information & 0.754 & 0.252 & & 0.064 & 0.147 & $0.008(-6.308)$ \\
\hline Understand health information & 0.578 & 0.552 & & 0.787 & 0.355 & \\
\hline Adjusted $\mathrm{R}^{2}$ & & & & & & 0.219 \\
\hline
\end{tabular}

Table 3b: Multiple linear regression analysis to identify associations between adherence to long-term therapy (MARS-5 and VAS-adherence) and Health Literacy Questionnaire scales.

beta: unstandardised coefficient; MA: multiple regression analysis with all independent variables; MaB: multiple regression analysis after including independent variables if univariate analysis $p<0.2$ and stepwise backward elimination if $p>0.05$; MARS-5: Medical Adherence Rating Scale-5; Uni: univariate regression analysis; VAS-adherence: Visual Analogue Scale adherence. 
systematic review investigating the role of different psychological challenges associated with QoL pointed out that stress and anxiety were negatively associated with QoL in CKD patients (Garcia-Llana et al. 2014). Other studies have reported that the experience of being in control of one's health situation is important for QoL in chronic illness (Kristofferzon et al. 2018). Understanding health information well enough to know what to do may provide CKD patients with a feeling of control and thereby reduce stress.

Our findings regarding the positive association between higher $\mathrm{HL}$ and better QoL is also following the conceptual model for $\mathrm{HL}$ (Sorensen et al. 2012) and underlines the importance of aiming to improve $\mathrm{HL}$ in CKD patients. However, we have previously reported that patients with low overall levels of $\mathrm{HL}$ have less education, more comorbidities, more prescribed medications and more depressive symptoms than patients with high overall levels of HL. These conditions may also affect QoL (Stømer et al. 2019). Whether poor QoL is a result of low overall $\mathrm{HL}$ or vice versa needs to be further explored.

To the best of our knowledge, this is the first study of CKD patients investigating the association between $\mathrm{HL}$ and adherence to long-term therapy, including both medication adherence and adherence to general lifestyle recommendations. A high level of $\mathrm{HL}$ is, in general, associated with more favourable health behaviours, such as greater adherence to dialysis treatment, better health resource utilisation and better medical adherence (Green et al. 2013; Lambert et al. 2015; Demian et al. 2016; Taylor et al. 2017). The mentioned associations are reflected by our results, showing stricter self-reported adherence to lifestyle recommendations among the high-level versus mid-level $\mathrm{HL}$ groups. However, the patients in the low-level HL group did not differ significantly in terms of adherence from the mid- and highlevel groups, which could be expected. A possible explanation for the lack of difference might be the small size of the low-level HL group (27 patients); more participants are probably needed to explore this further. The use of patient-reported outcome measurements does not exclude the possibility of idealisation of selfadherence (Magacho et al. 2011; Brown \& Bussell 2011; Lam \& Fresco 2015).

Patients' ability to engage with healthcare providers was positively associated with patients' adherence to lifestyle recommendations. A patient-healthcare provider partnership that is based on trust, mutual respect and room for compromise is described in previous studies as the core of all successful attempts to improve adherence behaviours (Martin et al. 2005; Fuertes et al. 2017a,b; Washington et al. 2016). Providing continuity of care is important in establishing such a sound alliance (Lin et al. 2015), and previous research reports that CKD patients receiving continuity of care are more adherent and have less disease progression (Chang et al. 2018). Together with previous research, our findings emphasise the importance of the relationship between patients and healthcare providers, which should be in focus when developing interventions to improve $\mathrm{HL}$ in CKD patients.

An interesting and unexpected finding was that the ability to find good health information was negatively associated with adherence to lifestyle recommendations provided by health care providers. One might assume that patients who are competent health information seekers may not seek advice from healthcare professionals to the same degree as patients with lower capacity in this area. Such an interpretation might arise due to the rapid proliferation of health information on the internet and the fact that a competent informant seeker might turn to the internet as the preferred source of health information instead of recommendations provided directly from the health care provider (Gualtieri 2009). Also, the healthcare system is currently evolving from being paternalistic to empowering patients; it would be interesting to explore further whether our result is an expression of patient empowerment or have other explanations such as lack of trust in, or difficulties in navigating the healthcare system.

We found no association between adherence to medical treatment and HL. Most patients reported very high degrees of medical adherence, which is in contrast to the results of previous research on medical adherence in CKD patients (Loghman-Adham 2003; Demian et al. 2016). However, when evaluating patients' medical prescription collection from the pharmacy, our findings were less encouraging and were following those of previous studies, e.g. the WHO's estimate of 50\% medical adherence (WHO 2003; Brown \& Bussell 2011). The inconsistency of medical adherence, as evaluated by subjective and objective assessment tools, shows that self-reported medical adherence data should be interpreted with caution and preferably in conjunction with an objective assessment tool (Lam \& Fresco 2015).

\section{IMPLICATIONS FOR PRACTICE}

We found that $\mathrm{HL}$ is of importance for both QoL and adherence in CKD patients. Hence, efforts to increase $\mathrm{HL}$ in this 
patient group are very important. On the basis of our results, healthcare providers working with CKD patients should focus on establishing a good relationship with patients and develop strategies to encourage patients to take an active role in managing their own health. Furthermore, healthcare providers should develop strategies for individualised and adapted health information aiming to provide patients with an understanding of essential aspects needed for coping with CKD.

At an organisational level, there is a new term in the field of $\mathrm{HL}$, called $\mathrm{HL}$ responsiveness (HLR). HLR means that healthcare organisations take responsibility for adapting the healthcare services to the HL needs and preferences of the population they serve, which requires awareness about $\mathrm{HL}$ as an important topic and individualised, tailored patient information adapted to the patients' specific needs (Trezona et al. 2017, 2018). From a longterm perspective, creating HLR organisations might improve QoL and adherence to long-term therapy in CKD patients.

\section{STRENGTHS AND LIMITATIONS}

The strengths of this study are the inclusion of CKD patients with a strong response rate of $78 \%$. The use of PROMs to assess $\mathrm{HL}$, QoL, and adherence to long-term therapy, acquired the perspectives of the patients, who we consider to be the most important stakeholders. The single-centred design is a strength that ensures that the study participants received similar healthcare services. The limitations of the study are the exclusion of patients unable to read and write in Norwegian, which may have excluded the most vulnerable patients. Further, we did not assess cognitive impairment, which is found to compromise the ability for selfmanaging in patients with advanced kidney disease (Lambert et al. 2017). Another limitation is the cross-sectional study design

\section{REF ERE N CES}

Altman D.G. (2018). Statistics for Medical Research, London, England: Tyler and Francis Ltd.

Andrade C.P., Cruz M.C., Urrutia M. et al. (2010). Evaluation of depressive symptoms in patients with chronic renal failure. Journal of Nephrology 23(2), 168-174.

Bailie G.R., Eisele G., Liu L. et al. (2005). Patterns of medication use in the RRI-CKD study: focus on medications with cardiovascular effects. Nephrology Dialysis Transplantation 20(6), 1110-1115.

Batterham R.W., Beauchamp A. \& Osbourne R.H. (2017). The International Encyclopedia of Public Health 2nd edn. Cambridge, MA: Elsevier Inc, Acadamic Press.

de Boer A.G.E.M., van Lanschot J.J.B., Stalmeier P.F.M. et al. (2004). Is a single-item visual analogue scale as valid, reliable and responsive that excludes the possibility of causal interpretation, although the study is highly hypothesis-generating.

\section{CONCLUSION}

Several dimensions of $\mathrm{HL}$ seems to be important for CKD patients' QoL and adherence to lifestyle recommendations. Healthcare services should focus on developing HLR organisations to increase QoL and adherence to long-term therapy. Additional studies with more participants and objective assessment tools are needed to investigate the relationship between CKD patients' HL and medical adherence.

\section{ACKNOWLEDGEMENTS}

The authors would like to thank the patients who generously participated in this study. We would also like to thank the staffs of the Nephrology Department at the Stavanger University Hospital for their cooperation during the data collection period, Dr. Joanna Haynes for language editing and last but not least, we thank Professor Jan Terje Kvaløy at the University of Stavanger for contributing with statistical advices.

\section{AUTHOR CONTRIBUTIONS}

UES: Principal Project Leader, conceived the study, collected and analyzed the data, drafted the manuscript, coordinated with co-authors, read and approved the final manuscript. AKW: Participated in the design, helped to analyse the data, drafted the manuscript, read and approved the final manuscript. LGG: Participated in the design, helped to analyse the data, drafted the manuscript, read and approved the final manuscript. KHU: Participated in the design and coordination, helped to analyse the data and drafted the manuscript, read and approved the final manuscript.

as multi-item scales in measuring quality of life? Quality of Life Research 13(2), 311-320.

Brown M.T. \& Bussell J.K. (2011). Medication adherence: WHO cares? Mayo Clinic Proceedings 86(4), 304-314.

Brück K., Stel V.S., Gambaro G. et al. (2016). CKD prevalence varies across the european general population. Journal of the American Society of Nephrology 27(7), 2135-2147.

Cavanaugh K.L., Wingard R.L., Hakim R.M. et al. (2010). Low health literacy associates with increased mortality in ESRD. Journal of the American Society of Nephrology 21(11), 1979-1985.

Chang P.Y., Chien L.N., Bai C.H. et al. (2018). Continuity of care with physicians and risk of subsequent hospitalization and end-stage renal disease in newly diagnosed type 2 diabetes 
mellitus patients. Therapeutics and Clinical Risk Management 14, 511-521.

Chang P.Y., Chien L.N. \& Lin Y.F. et al. (2015). Nonadherence of oral antihyperglycemic medication will increase risk of end-stage renal disease. Medicine (Baltimore) 94(47), e2051.

Chiu Y.W., Teitelbaum I., Misra M. et al. (2009). Pill burden, adherence, hyperphosphatemia, and quality of life in maintenance dialysis patients. Clinical Journal of the American Society of Nephrology 4(6), 1089-1096.

Clark S., Farrington K. \& Chilcot J. (2014). Nonadherence in dialysis patients: prevalence, measurement, outcome, and psychological determinants. Seminars Dialysis 27(1), 42-49.

Demian M.N., Shapiro R.J. \& Thornton W.L. (2016). An observational study of health literacy and medication adherence in adult kidney transplant recipients. Clinical Kidney Journal 9(6), 858-865.

Devraj R., Borrego M., Vilay A.M. et al. (2015). Relationship between health literacy and kidney function. Nephrology (Carlton) 20(5), 360-367.

Dodson S., Osicka T., Huang L. et al. (2016). Multifaceted assessment of health literacy in people receiving dialysis: associations with psychological stress and quality of life. Journal of Health Communication 21, 91-98.

Eckardt K.U., Coresh J., Devuyst O. et al. (2013). Evolving importance of kidney disease: from subspecialty to global health burden. The Lancet 382(9887), 158-169.

Fraser S.D.S., Roderick P.J., Casey M. et al. (2013). Prevalence and associations of limited health literacy in chronic kidney disease: a systematic review. Nephrology Dialysis Transplantation 28(1), 129-137.

Fructuoso M., Castro R., Oliveira L. et al. (2011). Quality of life in chronic kidney disease. Nefrología 31(1), 91-96.

Fuertes J.N., Rubinstein S., Reyes M. et al. (2017a). The physicianpatient working alliance in hemodialysis treatment. Behavioral Medicine 43(4), 242-250.

Fuertes J.N., Toporovsky A., Reyes M. et al. (2017b). The physicianpatient working alliance: theory, research, and future possibilities. Patient Education and Counseling 100(4), 610-615.

Furlanetto L.M., Mendlowicz M.V. \& Romildo Bueno J. (2005). The validity of the Beck Depression Inventory-Short Form as a screening and diagnostic instrument for moderate and severe depression in medical inpatients. Journal of Affective Disorders 86(1), 87-91.

Garcia-Llana H., Remor E., Del Peso G. et al. (2014). The role of depression, anxiety, stress and adherence to treatment in dialysis patients health-related quality of life: a systematic review of the literature. Nefrología 34(5), 637-657.

Green J.A., Mor M.K., Shields A.M. et al. (2013). Associations of health literacy with dialysis adherence and health resource utilization in patients receiving maintenance hemodialysis. American Journal of Kidney Diseases 62(1), 73-80.

Grubbs V., Gregorich S.E., Perez-Stable E.J. et al. (2009). Health literacy and access to kidney transplantation. Clinical Journal of the American Society of Nephrology 4(1), 195-200.
Gualtieri L.N. (2009). The doctor as the second opinion and the internet as the first. In Paper presented at the CHI '09 Extended Abstracts on Human Factors in Computing Systems, Boston, MA, USA.

Hallan S.I., Coresh J., Astor B.C. et al. (2006). International comparison of the relationship of chronic kidney disease prevalence and ESRD risk. Journal of the American Society of Nephrology 17(8), 2275-2284.

van der Heide I., Poureslami I., Mitic W. et al. (2018). Health literacy in chronic disease management: a matter of interaction. Journal of Clinical Epidemiology 102, 134-138.

Jónsdóttir H., Friis S., Horne R. et al. (2009). Beliefs about medications: measurement and relationship to adherence in patients with severe mental disorders. Acta Psychiatrica Scandinavica 119(1), 78-84.

K/DOQI. (2002). K/DOQI clinical practice guidelines for chronic kidney disease: evaluation, classification, and stratification. American Journal of Kidney Diseases 39(2 Suppl 1), S1-S266.

Kalichman S.C., Amaral C.M., Swetzes C. et al. (2009). A simple singleitem rating scale to measure medication adherence: further evidence for convergent validity. Journal of the International Association of Providers of AIDS Care (Chic) 8(6), 367-374.

Kazley A.S., Hund J.J., Simpson K.N. et al. (2015). Health literacy and kidney transplant outcomes. Progress in Transplantation 25(1), 85-90.

Kristofferzon M.L., Engstrom M. \& Nilsson A. (2018). Coping mediates the relationship between sense of coherence and mental quality of life in patients with chronic illness: a cross-sectional study. Quality of Life Research 27(7), 1855-1863.

Lam W.Y. \& Fresco P. (2015). Medication adherence measures: an overview. BioMed Research International 2015. 217047-12.

Lambert K., Mullan J., Mansfield K. et al. (2015). A Cross-sectional comparison of health literacy deficits among patients with chronic kidney disease. Journal of Health Communication 20(Suppl 2), 16-23.

Lambert K., Mullan J., Mansfield K. et al. (2017). Comparison of the extent and pattern of cognitive impairment among predialysis, dialysis and transplant patients: a cross-sectional study from Australia. Nephrology (Carlton) 22(11), 899-906.

Levey A.S. \& Coresh J. (2012). Chronic kidney disease. The Lancet 379(9811), 165-180.

Levey A.S., Schoolwerth A.C., Burrows N.R. et al. (2009). Comprehensive public health strategies for preventing the development, progression, and complications of CKD: report of an expert pane convened by the Centers for Disease Control and Prevention. American Journal of Kidney Diseases 53(3), 522-535.

Levey A.S., Stevens L.A., Schmid C.H. et al. (2009). A new equation to estimate glomerular filtration rate. Annals of Internal Medicine 150(9), 604-612.

Lin I.P., Wu S.C. \& Huang S.T. (2015). continuity of care and avoidable hospitalizations for chronic obstructive pulmonary disease (COPD). Journal of the American Board of Family Medicine 28(2), 222-230

Loghman-Adham M. (2003). Medication noncompliance in patients with chronic disease: issues in dialysis and renal transplantation. The American Journal of Managed Care 9(2), 155-171. 
Mackey L.M., Doody C., Werner E.L. et al. (2016). Self-management skills in chronic disease management: what role does health literacy have? Medical Decision Making 36(6), 741-759.

Magacho E.J.C., Ribeiro L.C., Chaoubah A. et al. (2011). Adherence to drug therapy in kidney disease. Brazilian Journal of Medical and Biological Research 44(3), 258-262.

Martin L.R., Williams S.L., Haskard K.B. et al. (2005). The challenge of patient adherence. Therapeutics and Clinical Risk Management 1(3), 189-199.

Muntner P., Judd S.E., Krousel-Wood M. et al. (2010). Low medication adherence and hypertension control among adults with CKD: data from the REGARDS (Reasons for Geographic and Racial Differences in Stroke) Study. American Journal of Kidney Diseases 56(3), 447-457.

Nabolsi M.M., Wardam L. \& Al-Halabi J.O. (2015). Quality of life, depression, adherence to treatment and illness perception of patients on haemodialysis. International Journal of Nursing Practice 21(1), 1-10.

Osborne R.H., Batterham R.W., Elsworth G.R. et al. (2013). The grounded psychometric development and initial validation of the Health Literacy Questionnaire (HLQ). BMC Public Health 13, 658.

Pagels A.A., Söderkvist B., Medin C. et al. (2012). Health-related quality of life in different stages of chronic kidney disease and at initiation of dialysis treatment. Health and Quality of Life Outcomes 10, 71.

Perlman R.L., Finkelstein F.O., Liu L. et al. (2005). Quality of life in chronic kidney disease (CKD): a cross-sectional analysis in the Renal Research Institute-CKD study. American Journal of Kidney Diseases 45(4), 658-666.

Ricardo A.C., Yang W., Lora C.M. et al. (2014). Limited health literacy is associated with low glomerular filtration in the Chronic Renal Insufficiency Cohort (CRIC) study. Clinical Nephrology 81(1), 30-37.

Roy L., White-Guay B., Dorais M. et al. (2013). Adherence to antihypertensive agents improves risk reduction of end-stage renal disease. Kidney International 84(3), 570-577.

Sjolander M., Eriksson M. \& Glader E.L. (2013). The association between patients' beliefs about medicines and adherence to drug treatment after stroke: a cross-sectional questionnaire survey. BMJ Open 3(9), e003551.

Stømer U.E., Gøransson L.G. \& Wahl A.K. et al. (2019). A crosssectional study of health literacy in patients with chronic kidney disease: associations with demographic and clinical variables. Nursing Open, 6(4), 1481-1490.

Sørensen K., Van den Broucke S., Fullam J. et al. (2012). Health literacy and public health: a systematic review and integration of definitions and models. BMC Public Health 12, 80.

Tangkiatkumjai M., Walker D.M., Praditpornsilpa K. et al. (2017). Association between medication adherence and clinical outcomes in patients with chronic kidney disease: a prospective cohort study. Clinical and Experimental Nephrology 21(3), 504-512.

Taylor D.M., Bradley J.A., Bradley C. et al. (2016). Limited health literacy in advanced kidney disease. Kidney International 90(3), 685-695.

Taylor D.M., Fraser S., Dudley C. et al. (2017). Health literacy and patient outcomes in chronic kidney disease: a systematic review. Nephrology Dialysis Transplantation 33(9), 1545-1558.
Taylor D.M., Fraser S.D.S., Bradley J.A. et al. (2017). A systematic review of the prevalence and associations of limited health literacy in CKD. Clinical Journal of the American Society of Nephrology 12(7), 1070-1084.

Trezona A., Dodson S. \& Osborne R.H. (2017). Development of the organisational health literacy responsiveness (Org-HLR) framework in collaboration with health and social services professionals. BMC Health Services Research 17(1), 513.

Trezona A., Dodson S. \& Osborne R.H. (2018). Development of the organisational health literacy responsiveness (Org-HLR) selfassessment tool and process. BMC Health Services Research 18(1), 694

Ward J. (1963). Application of a hierarchial grouping procedure to a problem of grouping profiles. Educational and Psychological Measurement 23, 69-81.

Ware J., Jr., Kosinski M. \& Keller S.D. (1996). A 12-item short-form health survey: construction of scales and preliminary tests of reliability and validity. Medical Care 34(3), 220-233.

Ware J.E., Jr., Gandek B., Kosinski M. et al. (1998). The equivalence of SF-36 summary health scores estimated using standard and country-specific algorithms in 10 countries: results from the IQOLA Project. International Quality of Life Assessment. Journal of Clinical Epidemiology 51(11), 1167-1170.

Ware J.E., Jr. \& Sherbourne C.D. (1992). The MOS 36-item short-form health survey (SF-36). I. Conceptual framework and item selection. Medical Care 30(6), 473-483.

Washington T., Zimmerman S. \& Browne T. (2016). Factors associated with chronic kidney disease self-management. Social Work in Public Health 31(2), 58-69.

Whaley-Connell A., Nistala R. \& Chaudhary K. (2011). The importance of early identification of chronic kidney disease. Missouri Medicine 108(1), 25-28.

WHO. (1998). The Health Promotion Glossary. http://www.who.int/ healthpromotion/about/HPR\%20Glossary\%201998.pdf?ua=1

WHO. (2003). Adherence to Long-Term Therapies, Evidence for Action. http://apps.who.int/iris/bitstream/10665/42682/1/92 41545992.pdf

WHO. (2013). Health Literacy, the Solid Facts. http://www.euro.who. int/en/publications/abstracts/health-literacy.-the-solid-facts

Østhus T.B., Preljevic V., Sandvik L. et al. (2012). Mortality and healthrelated quality of life in prevalent dialysis patients: comparison between 12-items and 36-items short-form health survey. Health and Quality of Life Outcomes 10(1), 46.

Østhus T.B.H., Dammen T., Sandvik L. et al. (2010). Health-related quality of life and depression in dialysis patients: associations with current smoking. Scandinavian Journal of Urology and Nephrology 44(1), 46-55.

\section{SUPPORTING INFORMATION}

Additional supporting information may be found online in the Supporting Information section at the end of the article. 